\title{
Review
}

Ophthalmic

Research

\section{Retinopathy of Type 1 Diabetes in Arab Countries: Systematic Review and Meta-Analysis}

\author{
Hatem Zayed $^{\mathrm{a}} \quad$ Ussama M. Abdel Motal $^{\mathrm{b}} \quad$ Akila Gopalakrishnan $^{\mathrm{a}}$ \\ Chinnayan Ponnuraja $^{c}$ C. George Priya Doss ${ }^{d} \quad$ Nasser Rizk $^{a} \quad$ Fatma M. Shebl $^{\mathrm{e}}$

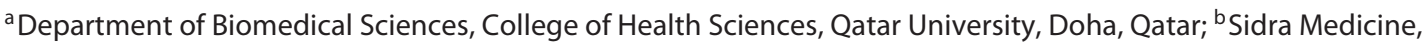 \\ Human Genetics, Translational Medicine, Qatar Foundation, Doha, Qatar; ' National Institute for Research in \\ Tuberculosis, Chennai, India; dVIT University, Vellore, India; ' Yale School of Public Health, New Haven, CT, USA
}

\section{Keywords}

Diabetic retinopathy - Type 1 diabetes · Complications ·

North Africa · Arab countries · Prevalence

\begin{abstract}
Aims: To conduct a systematic review and meta-analysis of retinopathy prevalence in patients with type 1 diabetes (T1D) in 22 Arab countries. Methods: We systematically searched 4 different literature databases (PubMed, Science Direct, Web of Science and Embase), from the date of inception until December 2017, to collect all the information about patients with T1D who developed retinopathy complications; for statistical analysis, we used MetaXL to evaluate the pooled prevalence estimate and the subgroup prevalence estimates employing double arcsine transformation and inverse variance heterogeneity models. Results: Our search strategy returned 475 studies, of which 39 met our inclusion criteria; of those, 16 were eligible for meta-analysis that were captured only in 15 Arab countries, through 45 years (1969-2014). The number of retinopathy patients was 396 out of 1,931 patients with T1D. The prevalence of retinopathy was $19 \%$ (95\% Cl 10-28\%). Substantial heterogeneity was observed (Q 240.78, $p<0.0001, \mathrm{I}^{2} 93.77 \%, 95 \% \mathrm{Cl}$
\end{abstract}

91.35-95.52\%); however, no single study considerably affected the overall pooled prevalence estimate. Conclusion: Almost one fifth of T1D patients in 15 Arab countries have diabetic retinopathy, therefore it is important to improve the care of patients with T1D and in Arab countries to avoid the development of such a devastating complication.

(c) 2018 S. Karger AG, Base

\section{Introduction}

It is estimated that more than 415 million people worldwide currently have diabetes and that number is predicted to rise to 642 million by 2040 [1]. It has become a chronic disease with several devastating complications. Diabetic retinopathy (DR) is a microvascular complication of diabetes and one of the leading causes of visual impairment worldwide, accounting for 93 million worldwide, with 28 million affected by vision-threatening DR [2]. With the expected global rise in the prevalence of diabetes $[1,3]$, the number of cases of DR and vision-threatening $\mathrm{DR}$, which includes severe nonproliferative $\mathrm{DR}$, proliferative DR, and diabetic macular edema, has been predicted to increase to 191.0 million and 56.3 million,

\section{KARGER}

(c) 2018 S. Karger AG, Basel

E-Mail karger@karger.com

www.karger.com/ore
Hatem Zayed, $\mathrm{PhD}$

Department of Biomedical Sciences, College of Health Sciences Qatar University

Doha (Qatar)

E-Mail hatem.zayed@qu.edu.qa 
Fig. 1. Flow diagram of selected articles.

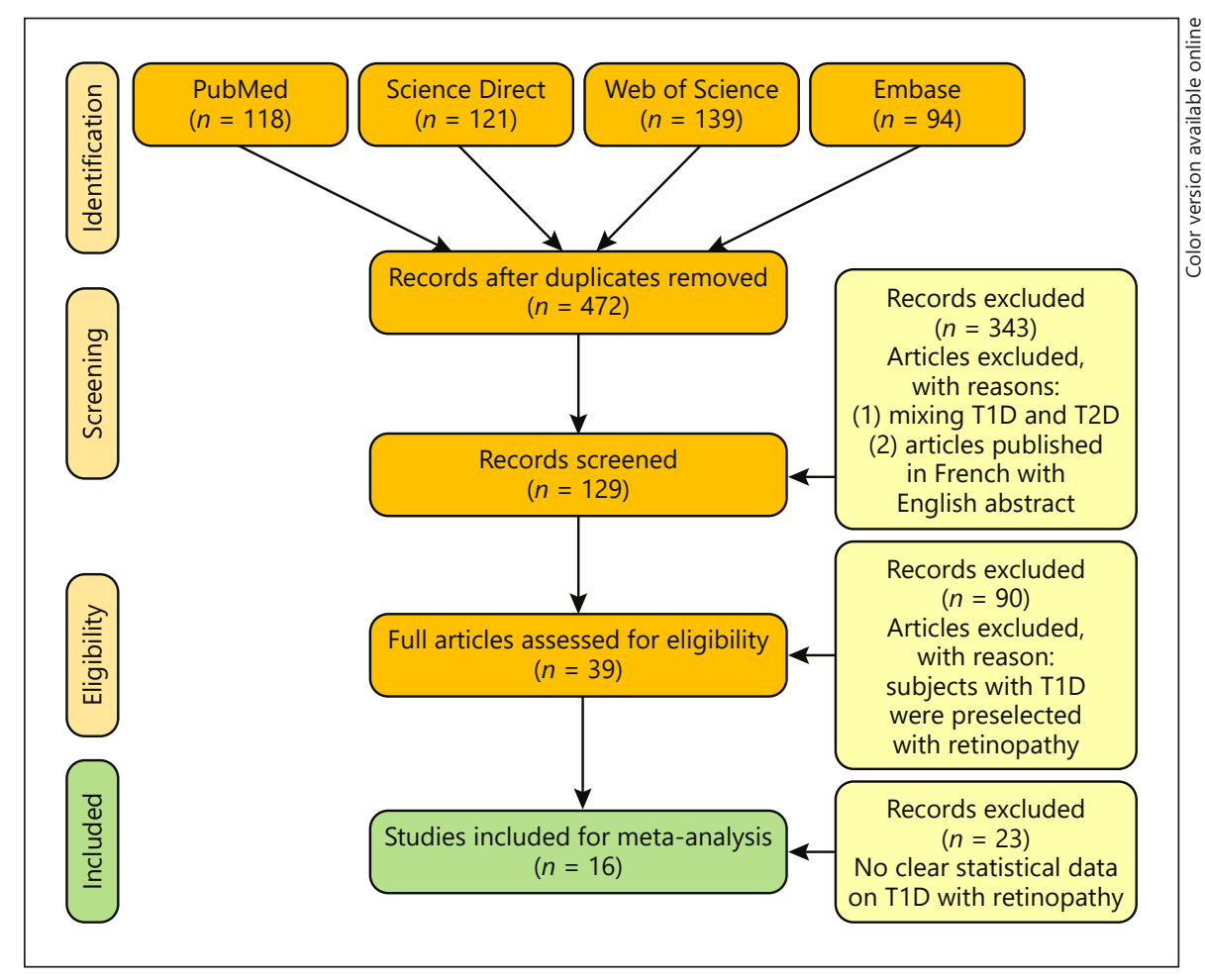

respectively, by 2030 [1]. Therefore, DR is declared as the priority disease in the VISION 2020 global elimination of blindness.

The Wisconsin Epidemiologic Study of Diabetic Retinopathy reported $3.6 \%$ of type 1 diabetes (T1D) and $1.6 \%$ of type 2 diabetes (T2D) patients as legally blind [4]. The prevalence of DR is higher in T1D compared to T2D, with sight-threatening retinopathy 2.5 times more common in T1D, independently of the duration of diabetes $[4,5]$. The major risk factors for $\mathrm{DR}$ pathogenesis include diabetes duration, $\mathrm{HbA}_{1 \mathrm{c}}$, high blood pressure, and dyslipidemia [2].

The Arab World is comprised of 22 Arab-speaking countries (http://www.arabbay.com/arabmap.htm). To date, the population of the Arab-speaking countries is approaching 0.5 billion [6]. In the Middle East and North Africa (mostly Arabs), 4 out of 10 adults with diabetes are undiagnosed [1]. Five Arab countries (United Arab Emirates, Bahrain, Kuwait, Qatar, and Saudi Arabia) rank within the top 15 nations in the world for highest rate of diabetes per capita (between 19.3 and 20\%), whereas Egypt, Oman, and Lebanon rank within the top 40 nations. Although diabetes in the Arab countries is considered as a major public health problem, T1D and its complications are not well studied [7-9]. To date, there are no accurate reports about the estimated prevalence of DR among Arab patients with T1D $[8,9]$. Therefore, in an effort to shed light onto such a serious complication of T1D among Arab patients, we performed a systematic review and meta-analysis on all reported literature from the time of inception until December 2017.

\section{Methods}

\section{Search Strategy}

We performed a systematic search using 4 different literature databases (PubMed, Science Direct, Web of Science, and Embase) (Fig. 1) from the time of inception until December 2017. The search terms used were: "Type 1 diabetes" and "Retinopathy" with the specific Arab country name, "microvascular complications" and "type 1 diabetes" and the name of each Arab country OR "IDDM" with "Diabetic Retinopathy" OR "T1D" OR "T1DM" with "Retinopathy" with the "name of each country" or "Middle East".

\section{Study Selection}

The inclusion criteria for our studies were: (1) only peer-reviewed research article, (2) the patients with T1D who presented with diabetic retinopathy, (3) only Arab patients residing in Arab countries. Our exclusion criteria were: (1) patients were a mix of T1D and T2D, with no clear distinction of retinopathy complication to either T1D or T2D, (2) retinopathy was only due to T2D, (3) no mention of the type of diabetes in the study. 
Table 1. Epidemiology of retinopathy in the Arab countries among subjects with T1D

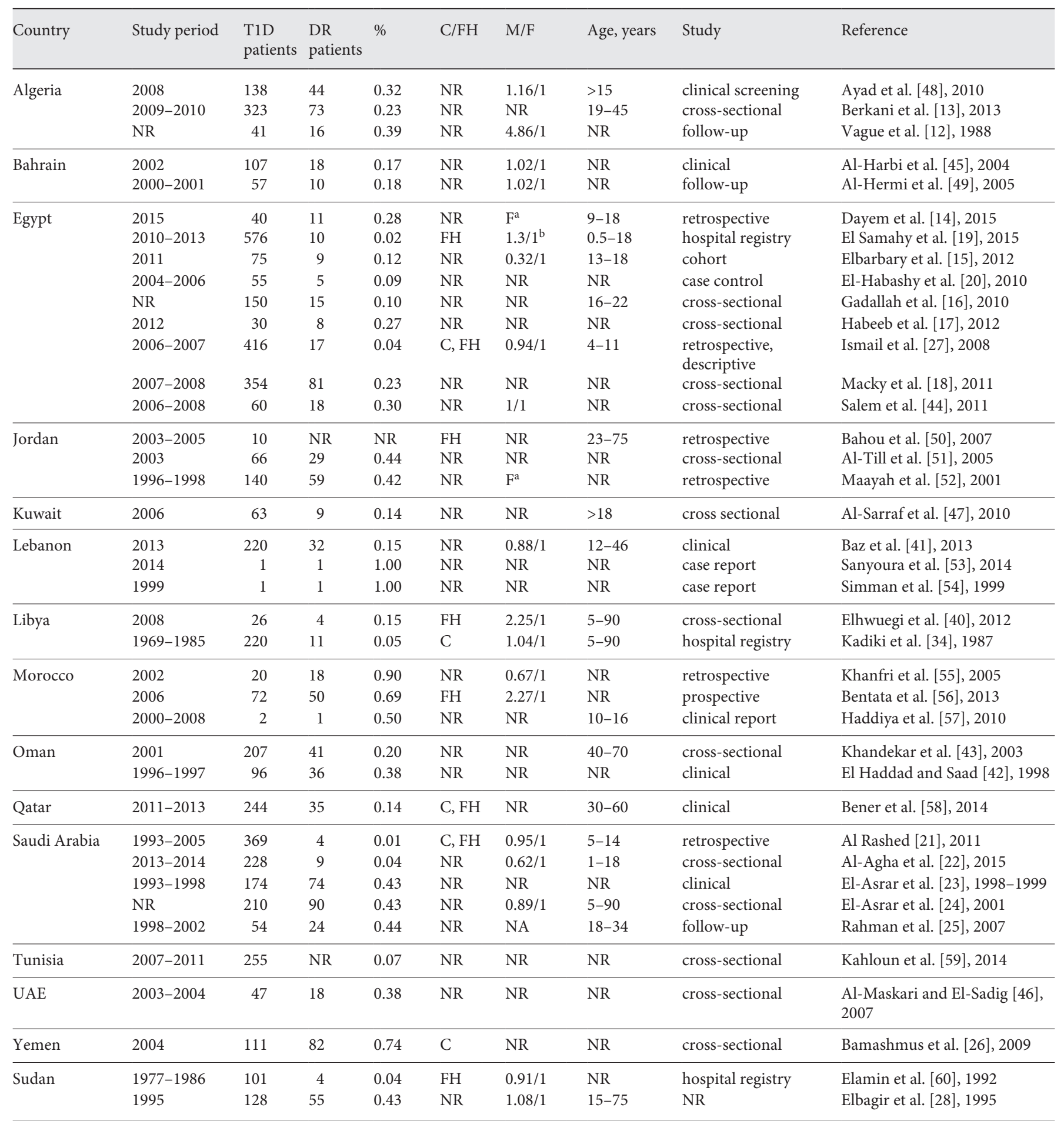

T1D, type 1 diabetes; $\mathrm{C} / \mathrm{FH}$, consanguinity/family history; M/F, male/female ratio; NR, not reported; NA, not available. When the values could not be concluded due to the mix between T1D and T2D or not reported, the value is assigned "NR".

${ }^{a}$ All patients were females. ${ }^{\mathrm{b}} 24$ patients of the enrolled 600 patients were T2D cases.

Retinopathy of Type 1 Diabetes in Arab Countries
Ophthalmic Res 2019;61:125-136

DOI: $10.1159 / 000489931$ 
Table 2. The prevalence of retinopathy complication among Arab subjects with T1D in the included studies

\begin{tabular}{|c|c|c|c|c|}
\hline \multirow[t]{2}{*}{ Study } & \multirow{2}{*}{$\begin{array}{l}\text { Preva- } \\
\text { lence }\end{array}$} & \multicolumn{2}{|c|}{$95 \% \mathrm{CI}$} & \multirow{2}{*}{$\begin{array}{l}\text { Weight, } \\
\%\end{array}$} \\
\hline & & lower & higher & \\
\hline Ayad et al. [48], 2010 & 0.32 & 0.24 & 0.40 & 7.14 \\
\hline Vague et al. [12], 1988 & 0.39 & 0.25 & 0.55 & 2.14 \\
\hline Al-Harbi et al. [45], 2004 & 0.17 & 0.10 & 0.25 & 5.54 \\
\hline Dayem et al. [14], 2015 & 0.28 & 0.15 & 0.43 & 2.09 \\
\hline El-Habashy et al. [20], 2010 & 0.09 & 0.03 & 0.18 & 2.86 \\
\hline Gadallah et al. [16], 2010 & 0.10 & 0.06 & 0.15 & 7.76 \\
\hline Ismail et al. [27], 2008 & 0.04 & 0.02 & 0.06 & 21.48 \\
\hline Salem et al. [44], 2011 & 0.30 & 0.19 & 0.42 & 3.12 \\
\hline Al-Sarraf el al. [47], 2010 & 0.14 & 0.07 & 0.24 & 3.27 \\
\hline Baz et al. [41], 2013 (French) & 0.15 & 0.10 & 0.20 & 11.37 \\
\hline Elhwuegi et al. [40], 2012 & 0.15 & 0.04 & 0.32 & 1.37 \\
\hline Khandekar et al. [43], 2003 & 0.20 & 0.15 & 0.26 & 10.70 \\
\hline El Haddad and Saad [42], 1998 & 0.38 & 0.28 & 0.47 & 4.98 \\
\hline El-Asrar et al. [23], 1998-1999 & 0.43 & 0.35 & 0.50 & 9.00 \\
\hline Elbagir et al. [28], 1995 & 0.42 & 0.32 & 0.52 & 4.72 \\
\hline Al-Maskari and El-Sadig [46], 2007 & 0.38 & 0.25 & 0.53 & 2.45 \\
\hline Pooled & 0.19 & 0.10 & 0.28 & 100.00 \\
\hline \multicolumn{5}{|l|}{ Statistics } \\
\hline $\mathrm{I}^{2}$ & 93.77 & 91.35 & 95.52 & \\
\hline Cochran's Q & 240.80 & & & \\
\hline$\chi^{2}(p$ value $)$ & 0.00 & & & \\
\hline
\end{tabular}

Due to the dearth of the studies found, we decided to capture all the studies which met the inclusion criteria without age limits; the citations were transferred to Endnote X7.1, then duplicates were removed, yielding 472 studies that were assessed for inclusion or exclusion as explained above and shown in the flow diagram (Fig. 1).

\section{Data Extraction}

To ensure that the data were captured correctly, 3 scientists (H.Z., U.M.A.M., and F.M.S.) independently reviewed the data. All the retrieved titles and abstracts identified were reviewed individually by each investigator. The screening of the research papers was performed using keywords such as: "retinopathy" OR "T1DM" OR "T1DM" OR "IDDM" OR "male" OR "female" OR "age" OR "family" OR "history" OR "relative” OR "cousin" OR "consang” OR "duration" OR "HbA $1 \mathrm{c}$ " OR "pressure". The captured data were tabulated after reaching a consensus among the authors.

\section{Data Synthesis and Statistical Analysis}

We used the double arcsine transformation to overcome the issue of the prevalence proportion close to extremities ( 0 and 1$)$, the resultant confidence limits outside the 0 and 1 range, and also the variance instability [10]. The presence of heterogeneity in the meta-analysis presents a challenge in estimating a pooled estimate due to the multiple sources of heterogeneity. Random effect models have been proposed; however, studies have shown that random effect models usually underestimate the statistical error and lead to spuriously overprecise estimates [11]. Two new alternatives have been proposed, including quality models and an inverse variance heterogeneity model. Because the information on the quality of some of the captured studies was not available, we used an inverse variance heterogeneity model, which is a fixed effect model with a quasi-likelihood-based variance structure. The effect size presented the prevalence of the retinopathy. For assessment of heterogeneity to determine whether the variation is above and beyond simple sampling error, we used the Q value and $\mathrm{I}^{2}$ (Table 2). To assess the source of heterogeneity, subgroup analyses were conducted by sample size, period, and region. In addition, we conducted meta-regression to evaluate the difference between subgroups. Funnel plot and Doi plot were generated to assess publication bias. The Luis Furuya-Kanamori (LFK) index was used as a quantitative measure of Doi plot asymmetry such that no asymmetry, minor asymmetry, and major asymmetry were defined as LFK index $\leq \pm 1, \pm 1<$ LFK index $\leq \pm 2$, and LFK index $> \pm 2$, respectively. Sensitivity analysis was conducted to assess the impact of excluding a study on the prevalence estimates as well as heterogeneity. We considered the excluded study as influential on the pooled prevalence estimate if the overall pooled prevalence estimate $95 \%$ confidence limits of the 16 studies (full-set) did not include the pooled prevalence estimate without the excluded study (i.e., reduced set of the remaining 15 studies). The MetaXL ${ }^{\complement} 2010$ 2016 program (version 5.3) was used for all the listed analyses.

\section{Results}

\section{Search Results}

Our search strategy captured 472 articles, of which 129 remained after removal of duplicates; of these, 39 were eligible for full article review (Table 1; Fig. 1). Of the 39 articles, 16 articles were included in the meta-analysis, which reported 396 T1D patients who developed DR out of 1,931 T1D patients who were the basis of the metaanalysis (Table 2). These patients were a mix of different ages, ranging from less than 1 year to 90 years (Table 1); in some studies the age specifications were not reported or it was not possible for us to determine the exact age range in the mix of diabetic patients, where the diabetes type was not clearly mentioned (Table 1).

\section{Diabetic Retinopathy in the Arab Countries}

We reviewed the full articles of the extracted 39 different studies across 15 Arab countries that were captured through our search strategy. In the other 7 Arab countries (Iraq, Palestine, Syria, Comoros, Djibouti, Mauritania, and Somalia), no data could be captured using our search strategy, even after using additional search through Google scholars and Google using the same search techniques mentioned in the Methods section.

We were able to extract the data from 37 full articles and 2 abstracts. Data were extracted from the abstracts because for the first study we could not get the complete 


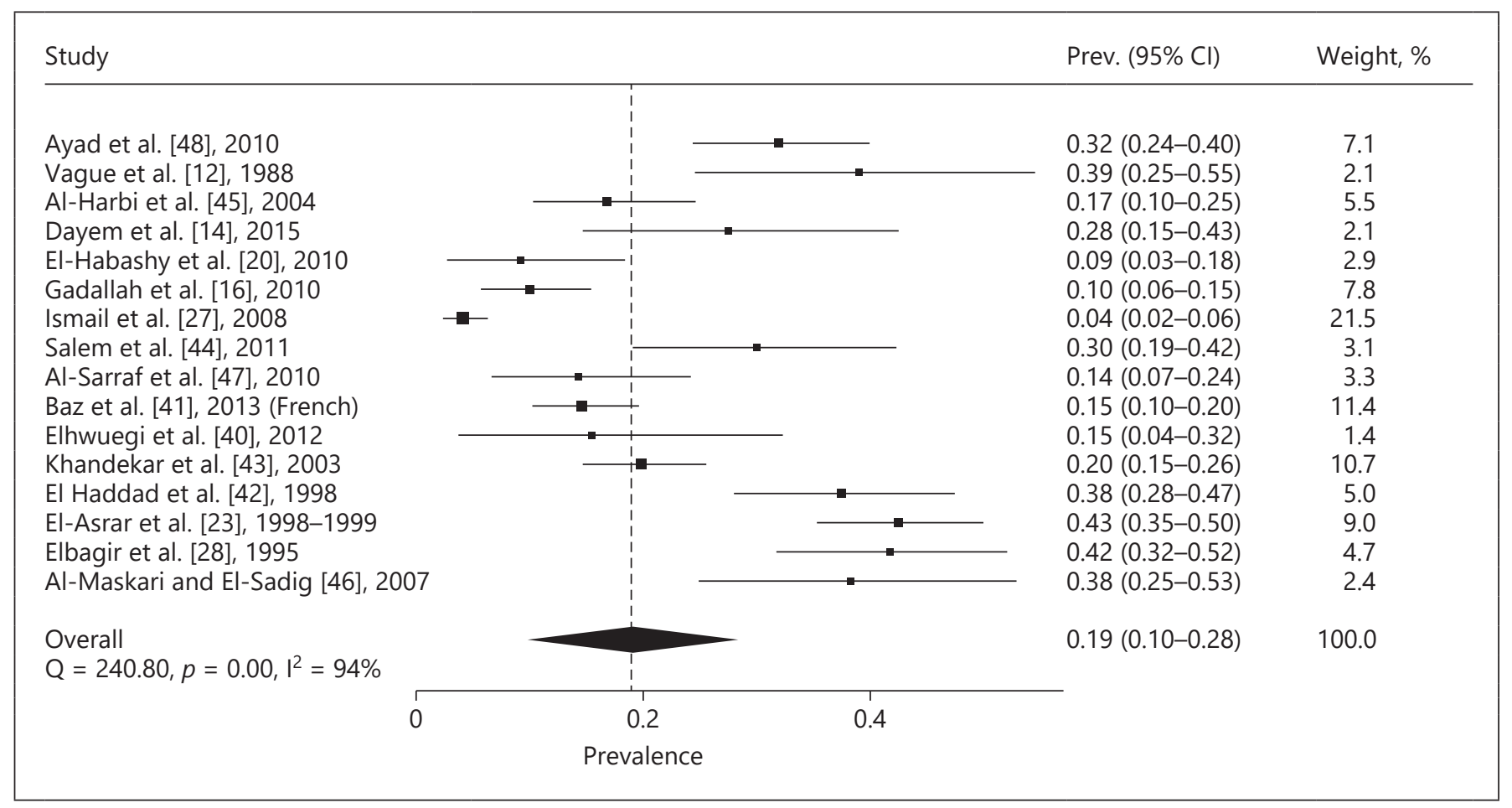

Fig. 2. Forest plot for the prevalence of retinopathy in subjects with type 1 diabetes. Forest plot of the 16 studies that investigated the association between retinopathy and T1D among Arab subjects using an inverse variance fixed-effects heterogeneity model. The effect size chosen is the prevalence. The midpoint of each segment is the estimate of prevalence. The size of the midpoint is propor- tional to the population of each study. The segment length shows the $95 \%$ confidence intervals (CI) for each study. The center of the diamond mark shows the prevalence in all the studies, and the edges show the $95 \%$ confidence intervals. Note that the prevalence is $19 \%$ (95\% CI $10-28)$. article [12], and for the second study, the article was in the French language but the abstract was in English [13]. Through 45 years (1969-2014), most of the studies reported were carried out in Egypt, with 9 studies [14-20], followed by Saudi Arabia with 5 studies [21-25] (Table 1). The rates of retinopathy among Arab patients with T1D ranged from low in Saudi Arabia [21] to high in Yemen [26] (Table 1).

\section{Meta-Analysis Results}

We captured 39 studies through our systematic search (Table 1). Of the 39 studies, 16 belong to only $10 \mathrm{Arab}$ countries and were eligible for meta-analysis (Table 2). The earliest study was reported from Algeria in 1988 and presented one of the highest prevalence rates (39\%) [12]. The prevalence of retinopathy ranged between 4 and $43 \%$, the lowest rates were reported from studies conducted in Egypt $[16,20,27]$, with the smallest prevalence proportion reported in a study conducted among 4- to 11-yearold children [27]. The highest prevalence was reported in studies from Saudi Arabia (43\%) [23] and Sudan (42\%) [28].

To investigate the association between diabetic retinopathy and Arab patients with T1D, we performed a meta-analysis using a fixed-effects, inverse variance heterogeneity model. Figure 2 shows the forest plot of the meta-analysis of the 16 studies. For each study, the midpoint of the segment is the estimate of prevalence, and the size of the midpoint is proportional to the population size while the segment length shows the $95 \%$ confidence intervals $(\mathrm{CI})$. The pooled prevalence is indicated by the center of the diamond mark, and the edges of the diamond show the $95 \%$ CI. The pooled estimate of the prevalence is 0.19 , which means $19 \%$ with a $95 \%$ CI of $10-28 \%$ (Table 2; Fig. 2).

To evaluate the heterogeneity among the 16 different studies and to determine whether the variation results from sampling error or true variation in the effect size, we performed the Q test and $\mathrm{I}^{2}$ (Table 2). Q was found to be $240.80(p<0.0001)$ which is much greater than the degree 
Table 3. Meta-regression of the association between period and sample size predictors and the prevalence of retinopathy complication among Arab subjects with T1D

\begin{tabular}{lllllll}
\hline & $\beta$ & SE & $t$ & $p$ value & \multicolumn{2}{l}{$95 \%$ CI } \\
\cline { 5 - 7 } & & & & & $\begin{array}{l}\text { lower } \\
\text { limit }\end{array}$ & $\begin{array}{l}\text { upper } \\
\text { limit }\end{array}$ \\
\hline Period & & & & 0.274 & & \\
$2001-2008$ & -0.37 & 0.22 & -1.72 & 0.129 & -0.89 & 0.14 \\
$2009+$ & -0.44 & 0.27 & -1.62 & 0.150 & -1.08 & 0.20 \\
$<2001$ & ref. & & & & & \\
\hline Sample size & & & & 0.102 & & \\
$51-100$ & -0.20 & 0.25 & -0.79 & 0.457 & -0.79 & 0.40 \\
$101-150$ & -0.20 & 0.26 & -0.75 & 0.476 & -0.81 & 0.42 \\
$150+$ & -0.53 & 0.21 & -2.48 & 0.042 & -1.04 & -0.02 \\
$<50$ & ref. & & & & & \\
\hline Region & & & & 0.113 & & \\
Africa & -0.27 & 0.15 & -1.81 & 0.113 & -0.63 & 0.08 \\
Asia & ref. & & & & & \\
\hline Constant & 1.69 & 0.34 & 4.99 & 0.002 & 0.89 & 2.50 \\
\hline
\end{tabular}

of freedom (df). Accordingly, this result suggests that there is an evidence of variation in the true effects (prevalence). Therefore, we investigated further, how much of the variance we observed was true variance using the $\mathrm{I}^{2}$ test. $\mathrm{I}^{2}$ was $93.77 \%$ (95\% CI 91.35-95.52\%) (Table 2), indicating that there is substantial heterogeneity, and about $94 \%$ of the observed variance in the effects is true.

\section{Subgroup Analyses and Meta-Regression}

Because of the heterogeneity in the results, we examined the effects by subgroups of the period of the data collection, sample size, and region. Studies conducted prior to 2001 reported the highest prevalence $(41 \%, 95 \%$ CI $36-$ $46 \%)$ and showed the least heterogeneity $\left(\mathrm{Q}=0.71, \mathrm{I}^{2}=\right.$ $0 \%)$ and was different from studies conducted later (Table 3; Fig. 3). There were no marked differences by sample size. The lowest heterogeneity was observed in the subgroup with less than 50 subjects $\left(\mathrm{Q}=9.66, \mathrm{I}^{2}=59 \%\right)$, whereas the prevalence $(37 \%, 95 \%$ CI $27-48 \%)$ was the highest among the different sample sizes (Table 3; Fig. 4).

Studies were divided by region into African and Asian Arab countries. The pooled prevalence from studies conducted in Africa of $14 \%(2-30 \%)$ was lower than the pooled prevalence from studies from Asia of 25\% (15$35 \%)$. However, the difference was not statistically significant (Table 3; Fig. 5).

\section{Sensitivity Analysis}

We also examined the effect of excluding one study at a time from the analysis. The study by Ismail et al. [27] had the biggest impact on prevalence, $\mathrm{Q}$, and $\mathrm{I}^{2}$ estimates. However, none of the prevalence estimates from the reduced-set estimates were outside the $95 \% \mathrm{CI}$ of the pooled prevalence estimate obtained from the full set (Table 4). Therefore, we concluded that no single study markedly affected the overall pooled prevalence estimate.

\section{Publication Bias}

The funnel and Doi plot indicated the presence of some bias. The LFK index was 1.86 , therefore we concluded that there was minor asymmetry (Fig. 6a, b).

\section{Discussion}

To our knowledge, this is the first systematic review and meta-analysis that scrupulously analyzed all the published data on the 22 Arab nations of Arab patients with T1D who had DR; our research strategy returned data on only 15 out of 22 Arab countries, from the time of inception to December 2017, through 45 years (1969-2014). In these patients, the rates of retinopathy ranged from low in Saudi Arabia [21] to high in Yemen [26] (Table 1). Among the 39 studies, we carefully selected 16 studies that met the eligible criteria for meta-analysis where they clearly stated the total sample size, the type of diabetes, and the characteristics of the subjects. Our meta-analysis pointed to a pooled prevalence estimate of $19 \%$. Interestingly, we observed that articles published before 2001 reported higher prevalence rates of DR among the Arab population than the rates reported in recent studies. This can be due to the increase in the level of higher education among Arabs and the spread of awareness about diabetes and its complications; another reason could be that the overall consanguinity rates among Arabs decrease, which has led to a decrease in the genetically transmitted diseases, including T1D and its complications.

In these 16 studies, the total number of subjects with T1D is 1,931, of whom 396 had retinopathy (Table 2); however, the heterogeneity measure (Q test of 240.80, $p$ value of 0.00 ) was highly significant. We estimated that $\mathrm{I}^{2}$ was $93.77 \%$ of the variation observed in the pooled estimate and was due to heterogeneity between studies, suggesting that there were variations across the studies. This relatively high heterogeneity could be attributed to several reasons, such as the extremes in prevalence rate between studies, the wide range of age groups, and the in- 


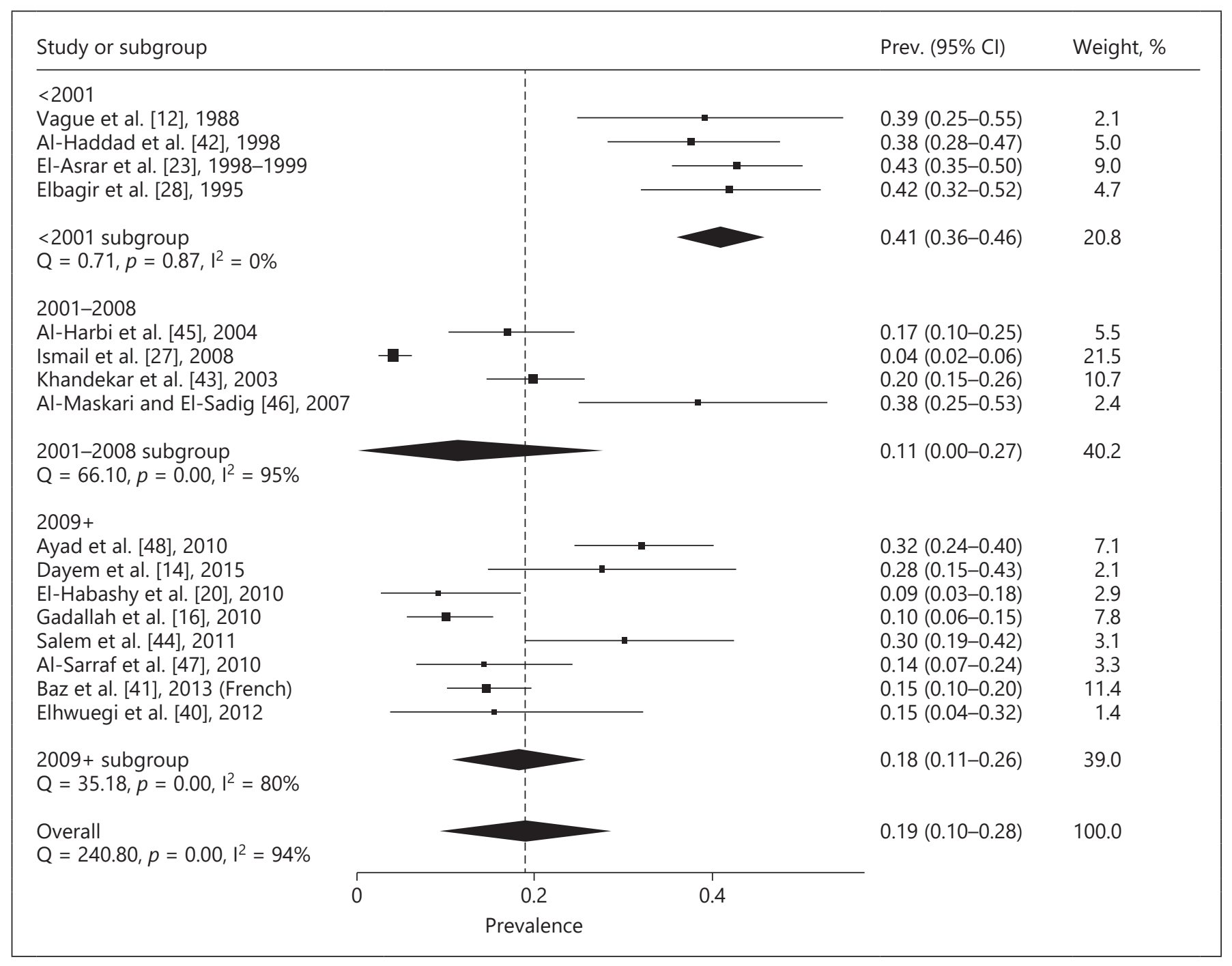

Fig. 3. Forest plot for the prevalence of retinopathy in subjects with type 1 diabetes by period of the study. Forest plot of the 16 studies that investigated the association between retinopathy and T1D among Arab subjects, stratified by 3 study periods. before 2001, 2001-2008, and 2009 and after.

ability to retrieve information by age category from some studies, the span of the studies' duration, and the regional variation. Our subgroup and meta-regression analysis did not indicate any significant difference by period, region, or sample size; however, heterogeneity was still observed within subgroups.

Consanguinity is part of the endogenous Arab culture, with a significant high prevalence of first-cousin marriage [29], which is still rising in some Arab countries [30], which is found to be responsible for the high prevalence of genetic diseases in the Arab countries [8,9,31-33]. Few studies $(n=5)$ reported the consanguinity [21,26, 27, 30, 34] (Table 1). The highest rate of DR was reported in a highly consanguineous cohort of patients from Yemen [26]; in the other studies, we were not able to capture the T1D or DR patients who belong to consanguineous families (Table 1), therefore we could not correlate consanguinity with the level of T1D or DR. However, consanguinity should be investigated further for their correlation with diabetic complications as it simplifies the mode of inheritance by reducing the complexity of multifactorial diseases including T1D [8], which may pave the way towards deciphering the genetic etiology of T1D and DR [8]. Moreover, the genomic revolution which is currently witnessed in the Arab world, with launching the Arab genome project $[35,36]$, is expected to contribute to our 


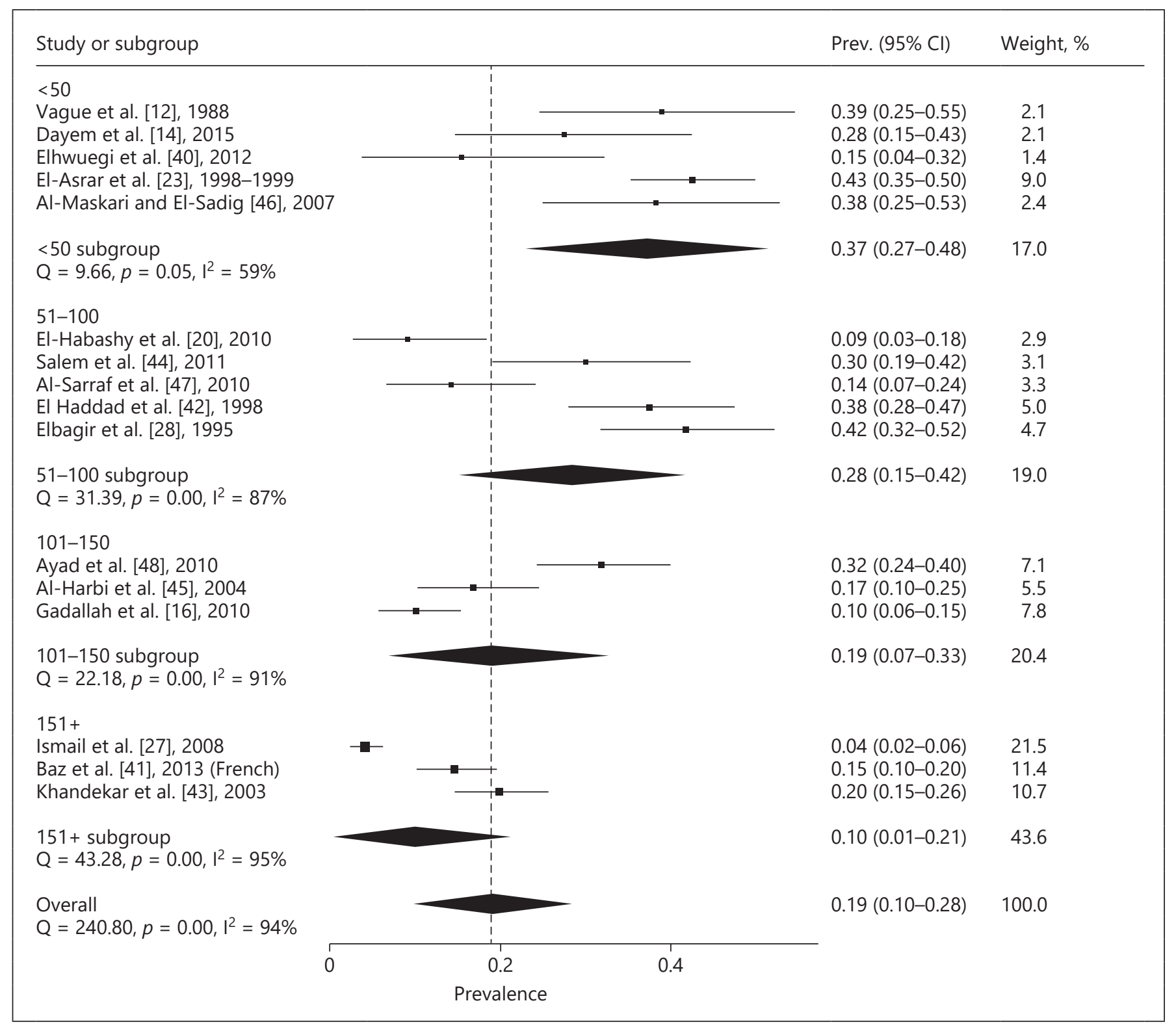

Fig. 4. Forest plot for the prevalence of retinopathy in subjects with type 1 diabetes by sample size of the study. Forest plot of the 16 studies that investigated the association between retinopathy and T1D among Arab subjects, stratified by 4 sample sizes: $<50,51-100,101-150$, and $\geq 151$.

understanding of the genetics of the diabetic complications.

The estimated prevalence rates of DR among the Arab population differ from those reported from different parts of the world; for example in the USA, the rates are estimated to be 74.9 and $82.3 \%$ in black and white individuals, respectively, and of vision-threatening retinopathy they were 30.0 and $32.2 \%$, respectively [5]. However, among Asian Indians, the DR rate was estimated as 53.3\% [37]. In European patients of Western Norway, the DR prevalence was estimated to be $61 \%$ [38], and in T1D patients from Thailand, the DR prevalence was found to be $21.6 \%$ [39]. These reports indicated that the prevalence rates of DR are higher than the rate observed in this study (19\%). However, given the limitations of our studies that an appreciable number of studies was excluded and that 


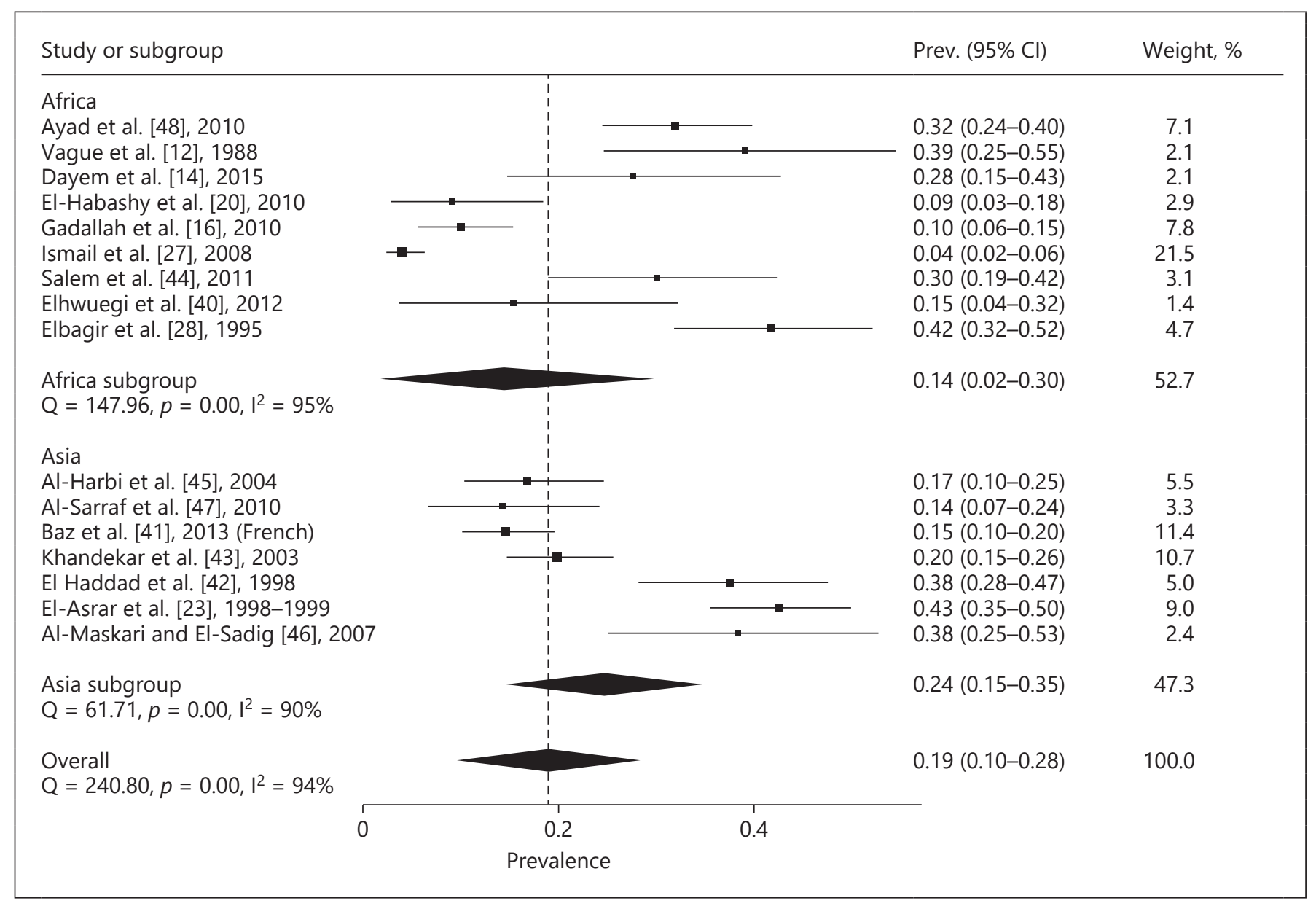

Fig. 5. Forest plot for the prevalence of retinopathy in subjects with type 1 diabetes by region of the study. Forest plot of the 16 studies that investigated the association between retinopathy and T1D among Arab subjects, stratified by 2 regions, Africa and Asia.

the published literature does not reflect the real image of DR among patients with T1D in Arab countries due to the poor publishing culture among Arab countries, we believe that the estimated prevalence here is underrated.

The strength of our study is that this is the first systematic review and meta-analysis to comprehensively study the retinopathy prevalence among Arab patients with T1D, providing a platform for improving the health care of Arab patients with diabetic complications and further epidemiological studies. However, we faced several limitations, including the small sample size in several studies $(n=4)[12,14,23,40]$; in addition, the age distribution varied considerably between studies $(n=11)[14,16,20$, $23,27,28,40-44]$ and was not reported in some of them $[12,23,45-48]$, which might contribute to the observed variation in the prevalence and also hindered our ability

Retinopathy of Type 1 Diabetes in Arab Countries to conduct subgroup analysis by age or to adjust for age in the meta-regression. More specifically, studies of younger age groups $(n=1)$ (age $4-11$ years) reported a low prevalence $(10 \%)$ [27], but studies which included older subjects $(n=2)$ reported a higher prevalence [23, 28]. Our search strategy yielded studies in only $15 \mathrm{Arab}$ countries out of 22, which limits the full benefit of this study, and this emphasizes the need for more comprehensive studies, which cover countries like Iraq, Palestine, Syria, Comoros, Djibouti, Mauritania, and Somalia. We understand that the DR risk is highly dependent upon diabetes duration and $\mathrm{HbA}_{1 c}$; however, these data were not available in the literature obtained to make sense of their association with DR. Finally, we had to exclude many articles where the distinction between T1D and T2D was not possible. 
Fig. 6. Publication bias: funnel plot (a) and Doi plot (b) for the prevalence of retinopathy in subjects with type 1 diabetes. Publication bias is said to be present if asymmetry in the plots is observed. The two plots revealed mild asymmetry. In addition, the LFK index was 1.86 denoting minor asymmetry.

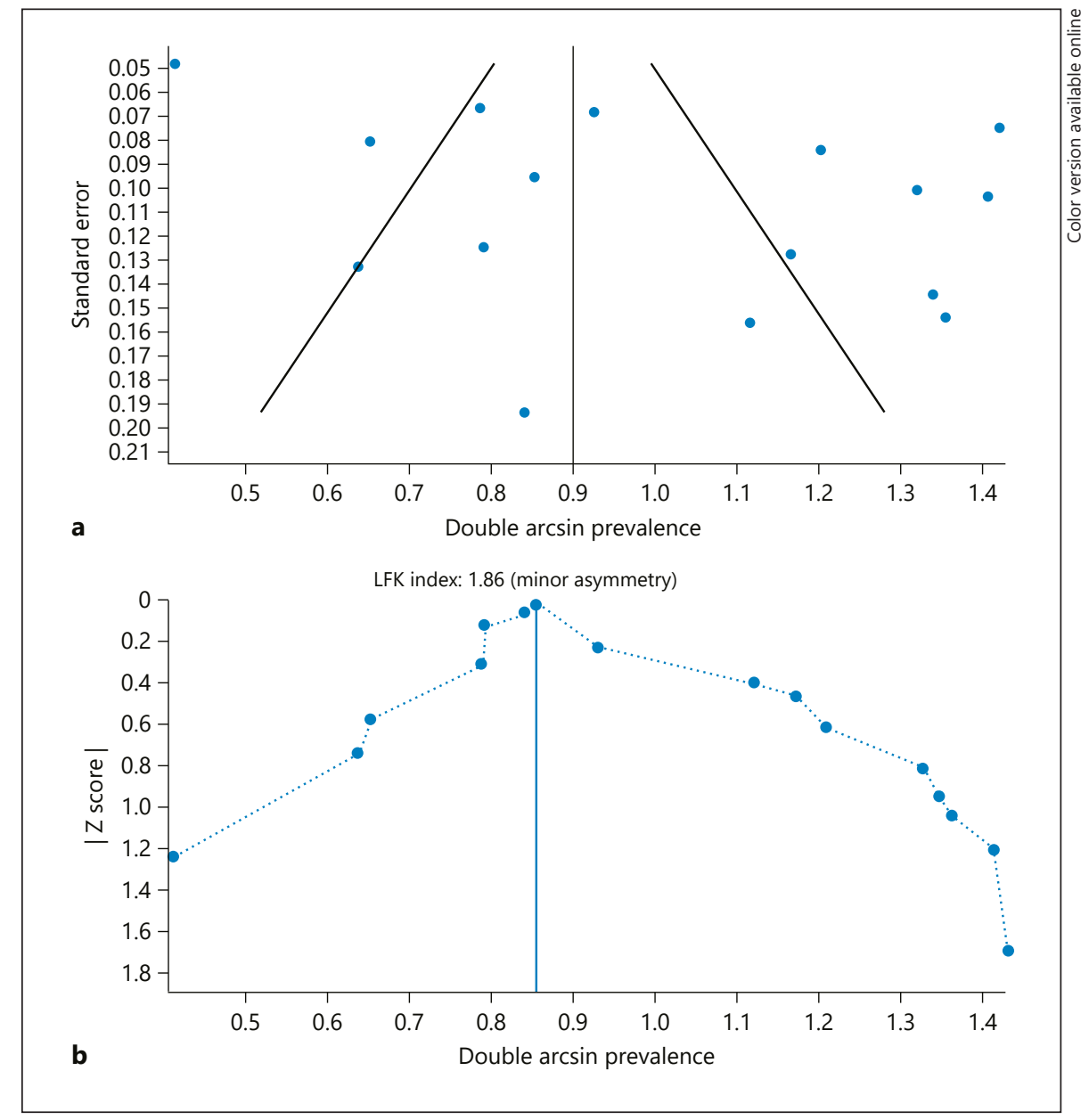

Table 4. Sensitivity analysis of the effect of removing each study on the pooled prevalence, and heterogeneity

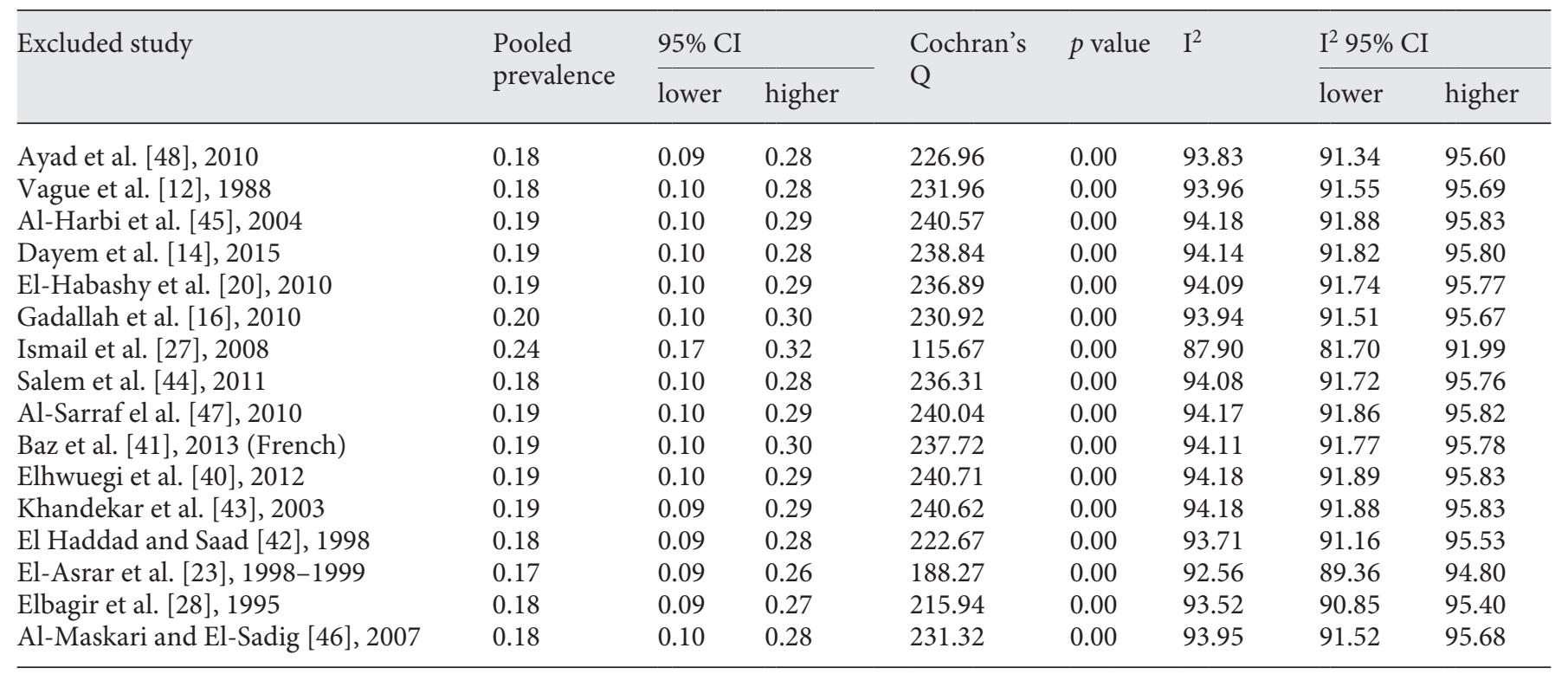


In conclusion, we present the first systematic review and meta-analysis of DR among Arab patients with T1D in 15 different Arab countries. Although our search strategy was broad, we were only able to find few reports compared to the scale of the problem in the Arab countries; our meta-analysis revealed that the prevalence is high (19\%) with significant variations among different Arab countries, even within the same country. Our findings will help to guide clinicians and scientists to individualize their efforts to protect patients from the devastating complication of T1D and increase the awareness of the high prevalence of retinopathy and the need to screen patients for retinopathy. The high degree of heterogeneity observed in our study indicates that there is a need for wellcontrolled studies to obtain an accurate estimation of the problem in the Arab countries. We believe that the actual prevalence in the Arab world is underestimated and rigorous controlled epidemiological studies should be undertaken in order to save a life now and in the future.

\section{Statement of Ethics}

Human and Animal Rights and Informed Consent: This article does not contain any studies with human or animal subjects performed by any of the authors.

\section{Disclosure Statement}

The authors have no conflict of interest to declare.

\section{Author Contributions}

H.Z. originated the study, acquired the data, analyzed, interpreted the data, and drafted the manuscript. F.M.S. analyzed and interpreted the data, and drafted the manuscript. U.M.A.M. and C.P. analyzed, interpreted, and critically reviewed the data. A.G. collected the data. C.G.P.D. collected the data and drafted the manuscript. N.R. drafted part of the manuscript.

\section{References}

1 International Diabetes Federation: Diabetes Atlas, ed 6. Brussels, International Diabetes Federation, 2015.

2 Yau JW, Rogers SL, Kawasaki R, Lamoureux EL, Kowalski JW, Bek T, et al: Global prevalence and major risk factors of diabetic retinopathy. Diabetes Care 2012;35:556-564.

3 Wild S, Roglic G, Green A, Sicree R, King H: Global prevalence of diabetes: estimates for the year 2000 and projections for 2030. Diabetes Care 2004;27:1047-1053.

4 Klein R, Klein BE, Moss SE, Davis MD, DeMets DL: The Wisconsin epidemiologic study of diabetic retinopathy. II. Prevalence and risk of diabetic retinopathy when age at diagnosis is less than 30 years. Arch Ophthalmol 1984;102:520-526.

5 Roy MS, Klein R, O'Colmain BJ, Klein BE, Moss SE, Kempen JH: The prevalence of diabetic retinopathy among adult type 1 diabetic persons in the United States. Arch Ophthalmol 2004;122:546-551.

6 The World Bank country and lending groups. 2015. www.worldbank.org.

7 Abdel-Motal UM, Abdelalim EM, AbouSaleh H, Zayed H: Neuropathy of type 1 diabetes in the Arab world: a systematic review and meta-analysis. Diabetes Res Clin Pract 2017;127:172-180.

8 Zayed H: Genetic epidemiology of type 1 diabetes in the 22 Arab countries. Curr Diabetes Rep 2016;16:37.

9 Zayed H, Ouhtit A, El Bekay R: An Arab registry for type 1 diabetes: global benefits for type 1 diabetes patients. Curr Med Res Opin 2016;4:1-4.

Retinopathy of Type 1 Diabetes in Arab Countries
10 Barendregt JJ, Doi SA, Lee YY, Norman RE, Vos T: Meta-analysis of prevalence. J Epidemiol Community Health 2013;67:974-978.

11 Al Khalaf MM, Thalib L, Doi SA: Combining heterogenous studies using the random-effects model is a mistake and leads to inconclusive meta-analyses. J Clin Epidemiol 2011;64: 119-123.

12 Vague P, Brunetti O, Valet AM, Attali I, Lassmann-Vague V, Vialettes B: Increased prevalence of neurologic complications among insulin dependent diabetic patients of Algerian origin. Diabete Metab 1988;14:706-711.

13 Berkani Z, Kitouni Y, Lakehal A, Roula D, Nezzal L, Kherroubi R, et al: Evaluation par rétinographie de la fréquence de la rétinopathie diabétique chez le diabétique de type 1 de la Wilaya de Constantine, Algérie. Méd Maladies Métab 2013;7:171-177.

14 Dayem SM, Nazif HK, Ei-Kader MA, ElTawil M: Study of adiponectin level in diabetic adolescent girls in relation to glycemic control and complication of diabetes. Open Access Maced J Med Sci 2015;3:613-618.

15 Elbarbary NS, El-Kabarity RH, Desouky ED: Cochleopathy in Egyptian adolescents with type 1 diabetes mellitus. Int J Pediatr Otorhinolaryngol 2012;76:1558-1564.

16 Gadallah F, Gadallah M, Ahmed I, El-Sayed E: Impact of overweight on type 1 diabetes among university students in Egypt. Nat Sci 2010;8:52-59.

17 Habeeb NM, Youssef OI, Saab AA, El Hadidi ES: Adiponectin as a marker of complications in type I diabetes. Indian Pediatrics 2012;49: 277-280.
18 Macky TA, Khater N, Al-Zamil MA, El Fishawy H, Soliman MM: Epidemiology of diabetic retinopathy in Egypt: a hospital-based study. Ophthalmic Res 2011;45:73-78.

19 El Samahy MH, Elbarbary NS, Elmorsi HM: Current status of diabetes management, glycemic control and complications in children and adolescents with diabetes in Egypt. Where do we stand now? And where do we go from here? Diabetes Res Clin Pract 2015;107: 370-376.

20 El-Habashy SA, Matter RM, El-Hadidi ES, Afifi HR: Plasma adrenomedullin level in Egyptian children and adolescents with type 1 diabetes mellitus: relationship to microvascular complications. Diabetol Metab Syndr 2010;2:12.

21 Al Rashed AM: Pattern of presentation in type 1 diabetic patients at the diabetes center of a university hospital. Ann Saudi Med 2011;31: 243-249.

22 Al-Agha AE, Alafif MM, Abd-Elhameed IA: Glycemic control, complications, and associated autoimmune diseases in children and adolescents with type 1 diabetes in Jeddah, Saudi Arabia. Saudi Med J 2015;36:26-31.

23 El-Asrar AM, Al-Rubeaan KA, Al-Amro SA, Kangave D, Moharram OA: Risk factors for diabetic retinopathy among Saudi diabetics. Int Ophthalmol 1998-1999;22:155-161.

24 El-Asrar AM, Al-Rubeaan KA, Al-Amro SA, Moharram OA, Kangave D: Retinopathy as a predictor of other diabetic complications. Int Ophthalmol 2001;24:1-11. 
25 Rahman W, Rahman FZ, Yassin S, Al-Suleiman SA, Rahman J: Progression of retinopathy during pregnancy in type 1 diabetes mellitus. Clin Exp Ophthalmol 2007;35:231-236.

26 Bamashmus MA, Gunaid AA, Khandekar RB: Diabetic retinopathy, visual impairment and ocular status among patients with diabetes mellitus in Yemen: a hospital-based study. Indian J Ophthalmol 2009;57:293-298.

27 Ismail NA, Kasem OM, Abou-El-Asrar M, ElSamahy MH: Epidemiology and management of type 1 diabetes mellitus at the Ain Shams University pediatric hospital. J Egypt Public Health Assoc 2008;83:107-132.

28 Elbagir MN, Eltom MA, Mahadi EO, Berne C: Pattern of long-term complications in Sudanese insulin-treated diabetic patients. Diabetes Res Clin Pract 1995;30:59-67.

29 Tadmouri GO, Nair P, Obeid T, Al Ali MT, Al Khaja N, Hamamy HA: Consanguinity and reproductive health among Arabs. Reprod Health 2009;6:17.

30 Bener A, Alali KA: Consanguineous marriage in a newly developed country: the Qatari population. J Biosoc Sci 2006;38:239-246.

31 Al-Gazali L, Hamamy H, Al-Arrayad S: Genetic disorders in the Arab world. BMJ 2006; 333:831-834.

32 Doss CG, Alasmar DR, Bux RI, Sneha P, Bakhsh FD, Al-Azwani I, et al: Genetic epidemiology of glucose-6-dehydrogenase deficiency in the Arab World. Sci Rep 2016;6: 37284.

33 Mosaeilhy A, Mohamed MM, Priya Doss CG, El Abd HS, Gamal R, Zaki OK, et al: Genotype-phenotype correlation in 18 Egyptian patients with glutaric acidemia type I. Metab Brain Dis 2017;32:1417-1426.

34 Kadiki OA, Gerryo SE, Khan MM: Childhood diabetes mellitus in Benghazi (Libya). J Trop Pediatr 1987;33:136-139.

35 Zayed H: The Arab genome: health and wealth. Gene 2016;592:239-243.

36 Zayed H: The Qatar genome project: translation of whole-genome sequencing into clinical practice. Int J Clin Pract 2016;70:832-834.

37 Rajalakshmi R, Amutha A, Ranjani H, Ali MK, Unnikrishnan R, Anjana RM, et al: Prevalence and risk factors for diabetic retinopathy in Asian Indians with young onset type 1 and type 2 diabetes. J Diabetes Complications 2014;28:291-297.
38 Jansson RW, Hufthammer KO, Krohn J: Diabetic retinopathy in type 1 diabetes patients in Western Norway. Acta Ophthalmol 2018, Epub ahead of print.

39 Chetthakul T, Likitmaskul S, Plengvidhya N, Suwanwalaikorn S, Kosachunhanun N, Deerochanawong C, et al: Thailand diabetes registry project: prevalence of diabetic retinopathy and associated factors in type 1 diabetes mellitus. J Med Assoc Thailand/Chotmaihet Thangphaet 2006;89(suppl 1):S17S26.

40 Elhwuegi AS, Darez AA, Langa AM, Bashaga NA: Cross-sectional pilot study about the health status of diabetic patients in city of Misurata, Libya. Afr Health Sci 2012;12:81-86.

41 Baz PC, Antoun J, Haddad N, Kourie H: Prevalence and risk factors of retinopathy in a young Lebanese population with well controlled type I diabetes (in French). J Med Liban 2013;61:132-137.

42 El Haddad OA, Saad MK: Prevalence and risk factors for diabetic retinopathy among Omani diabetics. Br J Ophthalmol 1998;82:901-906.

43 Khandekar R, Al Lawatii J, Mohammed AJ, Al Raisi A: Diabetic retinopathy in Oman: a hospital based study. Br J Ophthalmol 2003;87: 1061-1064.

44 Salem M, Moneir I, Adly AM, Esmat K: Study of coronary artery calcification risk in Egyptian adolescents with type-1 diabetes. Acta Diabetol 2011;48:41-53.

45 Al-Harbi EM, Abbassi AJ, Tamim H, al-Jenaidi F, Kooheji M, Kamal M, et al: Specific HLA-DRB and -DQB alleles and haplotypes confer disease susceptibility or resistance in Bahraini type 1 diabetes patients. Clin Diagn Lab Immunol 2004;11:292-296.

46 Al-Maskari F, El-Sadig M: Prevalence of diabetic retinopathy in the United Arab Emirates: a cross-sectional survey. BMC Ophthalmol 2007;7:11.

47 Al-Sarraf A, Al-Bannai S, Al-Furaih A, ElShazly M: Prevalence and factors associated with diabetic retinopathy, a multi-centric study in Kuwait. Bull Alex Fac Med 2010;46: 99-108.

48 Ayad F, Belhadj M, Paries J, Attali JR, Valensi P: Association between cardiac autonomic neuropathy and hypertension and its potential influence on diabetic complications. Diabet Med 2010;27:804-811.
49 Al-Hermi BE, Al-Abbasi AM, Rajab MH, AlJenaidi FA, Al-Ekri ZE: Diabetic nephropathy in children with type 1 diabetes mellitus in Bahrain. Saudi Med J 2005;26:294-297.

50 Bahou YG: A clinical and electrodiagnostic study of diabetic neuropathy at Jordan University Hospital. Neurosciences (Riyadh) 2007;12:215-220.

51 Al-Till MI, Al-Bdour MD, Ajlouni KM: Prevalence of blindness and visual impairment among Jordanian diabetics. Eur J Ophthalmol 2005; 15:62-68

52 Maayah J, Shammas A, Haddadin A: Effect of pregnancy on diabetic retinopathy. Bahrain Med Bull 2001;23:163-165.

53 Sanyoura M, Woudstra C, Halaby G, et al: A novel ALMS1 splice mutation in a non-obese juvenile-onset insulin-dependent syndromic diabetic patient. Eur J Hum Genet 2014;22: 140-143.

54 Simaan EM, Mikati MA, Touma EH, Rotig A: Unusual presentation of Kearns-Sayre syndrome in early childhood. Pediatr Neurol 1999;21:830-831.

55 Khanfri N, Medkouri G, Aghai R, et al: Diabetic nephropathy in hemodialysis patients in Casablanca. Saudi J Kidney Dis Transpl 2005; 16:89-92.

56 Bentata Y, Haddiya I, Latrech H, Serraj K, Abouqal R: Progression of diabetic nephropathy, risk of end-stage renal disease and mortality in patients with type-1 diabetes. Saudi J Kidney Dis Transpl 2013;24:392-402.

57 Haddiya I, Hamzaoui H, Al Hamany Z, et al: Isolated nondiabetic renal disease in diabetic patients: a Moroccan report. Saudi J Kidney Dis Transpl 2010;21:555-558.

58 Bener A, Al-Laftah F, Al-Hamaq AOAA, Daghash M, Abdullatef WK: A study of diabetes complications in an endogamous population: an emerging public health burden. Diabetes Metab Syndr 2014;8:108-114.

59 Kahloun R, Jelliti B, Zaouali S, et al: Prevalence and causes of visual impairment in diabetic patients in Tunisia, North Africa. Eye (Lond) 2014;28:986-991.

60 Elamin A, Altahir H, Ismail B, Tuvemo T: Clinical pattern of childhood type 1 (insulindependent) diabetes mellitus in the Sudan. Diabetologia 1992;35:645-648. 